\title{
The spectrum of pulmonary arterial hypertension in adults with congenital heart disease: management from a physician and nurse specialist perspective
}

\author{
Konstantinos Dimopoulos ${ }^{*}$ (D), Carl Harries and Lisa Parfitt
}

\begin{abstract}
Congenital heart disease (CHD) is one of the most common causes of pulmonary arterial hypertension (PAH), with a prevalence nearing that of idiopathic PAH in registries. Despite similarities in pulmonary vascular pathology, PAH$\mathrm{CHD}$ differs from idiopathic PAH and other types of PAH. In fact, $\mathrm{PAH}-\mathrm{CHD}$ is a term that includes a wide spectrum of conditions and pathophysiologies, ranging from Eisenmenger syndrome to milder forms of PAH with systemic-topulmonary shunts, to those with previously repaired defects. Significant expertise in both CHD and PAH is required to manage these patients. We provide an overview of the modern management of the wide spectrum of PAH-CHD in adults, both from a physician and clinical nurse specialist perspective.
\end{abstract}

\section{Background}

Congenital heart disease (CHD) is one of the most common causes of pulmonary arterial hypertension (PAH) [1]. Any type of CHD that allows significant systemic-to-pulmonary shunt to occur, can ultimately lead to the development of PAH and affecting outcome $[2,3]$. Exposure of the pulmonary circulation to high flow and pressure can trigger the development of pulmonary vascular disease (PVD). Despite significant similarities in pulmonary pathology, PAH-CHD differs from other types on PAH and expertise in both CHD and $\mathrm{PAH}$ is required for optimal management. While conventional measures and avoidance of pitfalls remain extremely important, the recent availability of $\mathrm{PAH}$ therapies has revolutionized the treatment of PAH-CHD $[4,5]$. We provide an overview of the modern management of the entire spectrum of PAH-CHD in adults, both from a physician and clinical nurse specialist perspective.

\footnotetext{
* Correspondence: k.dimopoulos02@gmail.com

Adult Congenital Heart Centre and Centre for Pulmonary Hypertension, Royal Brompton Hospital, NIHR Cardiovascular BRU and Imperial College London, Sydney Street, London SW3 6NP, UK
}

\section{Clinical classification of PAH-CHD}

PAH-CHD represents a wide spectrum of conditions, which differ in terms of the severity of PAH and the underlying cardiac anatomy and physiology. For this reason, PAH guidelines have proposed the following classification for PAH-CHD (Table 1) [2, 6].

\section{A. Eisenmenger syndrome}

Eisenmenger syndrome (ES) is the extreme manifestation of PAH-CHD in terms of the severity of the PVD. ES is a multiorgan disease and is characterised by significant morbidity and mortality, even though prognosis may not be as adverse as that of patients in group D (PAH-CHD post-repair) [7-11].

ES is characterised by cyanosis at rest or on effort. Chronic cyanosis, together with PAH and the underlying congenital heart defect is responsible for the significant morbidity and mortality of this important symptom of ES and affects patients' quality of life [12-14]. Tolerance to effort is extremely limited in these patients, with an average peak oxygen consumption well below $15 \mathrm{ml} / \mathrm{kg} / \mathrm{min}$, frequently less than half that predicted for healthy 
Table 1 The wide spectrum of PAH-CHD

\begin{tabular}{|c|c|}
\hline A. Eisenmenger syndrome & $\begin{array}{l}\text { Includes all systemic-to-pulmonary } \\
\text { shunts due to large defects leading } \\
\text { to a severe increase in pulmonary } \\
\text { vascular resistance (PVR) and reversal } \\
\text { of the shunt, which becomes } \\
\text { pulmonary-to-systemic or bidirectional. } \\
\text { Cyanosis, erythrocytosis, and multiple } \\
\text { organ involvement are common. }\end{array}$ \\
\hline $\begin{array}{l}\text { B. Pulmonary arterial } \\
\text { hypertension associated } \\
\text { with systemic-to- } \\
\text { pulmonary shunts }\end{array}$ & $\begin{array}{l}\text { Patients with moderate to large } \\
\text { defects, in which the increase in PVR } \\
\text { is mild to moderate, left-right shunt } \\
\text { is still present and there is no cyanosis } \\
\text { at rest. }\end{array}$ \\
\hline $\begin{array}{l}\text { C. Pulmonary arterial } \\
\text { hypertension with } \\
\text { small defects }\end{array}$ & $\begin{array}{l}\text { Patients with small (coexistent) } \\
\text { defects and a clinical picture very } \\
\text { similar to idiopathic PAH. Includes: } \\
\text { - ventricular septal defects } \\
<1 \mathrm{~cm} \text { in diameter } \\
\text { - atrial septal defects } \\
<2 \mathrm{~cm} \text { in diameter }\end{array}$ \\
\hline $\begin{array}{l}\text { D. Pulmonary arterial } \\
\text { hypertension after } \\
\text { corrective cardiac } \\
\text { surgery }\end{array}$ & $\begin{array}{l}\text { Congenital heart disease has been } \\
\text { corrected but PAH has persisted } \\
\text { after surgery, or has developed } \\
\text { several months or years after surgery } \\
\text { in the absence of a significant } \\
\text { residual defect. }\end{array}$ \\
\hline
\end{tabular}

Other types of pulmonary vascular disease in $\mathrm{CHD}$ patients

Segmental pulmonary arterial hypertension

Pulmonary vascular disease in Fontan patients
Segments of the lung vasculature develop pulmonary vascular disease, while other parts may be normally perfused, hyper or hypoperfused. This is now included in group 5 after Nice 2013 [6]

A rise in PVR may occur in patients with a Fontan-type circulation and low pulmonary blood flow, despite low pulmonary arterial pressures.

individuals. Despite this, ES patients often deny significant limitation, due to adaptation of their ordinary activities to their ability from a young age. For this reason, physicians and nurses are urged to assess functional class by means of examples of physical effort, distance walked to landmarks, or comparison to peers [9]. This has implications on deciding management, including the use of $\mathrm{PAH}$ therapies.

ES also has significant hematologic effects, mainly related to chronic, long-standing cyanosis $[15,16]$. Hypoxia in ES typically leads to secondary erythrocytosis, i.e. an isolated rise in red cell count and haemoglobin concentration. This is nowadays felt to be a compensatory mechanism, aimed at increasing the oxygen-carrying capacity of the blood and hence increase delivery of oxygen to the tissues, with the result of increased blood viscosity [1, 17]. The latter has in the past raised great concerns, and routine venesections were performed to avoid the onset of hyperviscosity symptoms or embolic events [18]. However, current practice has moved away from venesections, which are rarely required when very high haematocrit levels are associated with severe hyperviscosity symptoms in the absence of dehydration. The reason for this change in practice has been the realisation that erythrocytosis is a beneficial compensatory mechanism aimed at increasing the blood's oxygen carrying capacity and, hence, oxygen delivery to tissues. Indeed, there is some evidence to suggest that routine venesections leading to significant iron deficiency may even promote cerebrovascular events [18]. Erythrocytosis is often associated with thrombocytopenia and possibly platelet dysfunction. Moreover, coagulation abnormalities can be present in ES, creating a paradoxic state of hypercoagulability (frequently seen as in situ thrombosis within the pulmonary arteries) but also tendency to bleed (epistaxis, haemoptysis, gastrointestinal bleeds, menorrhagia, etc.). For this reason, the use of anticoagulants remains controversial in ES [19]. In our centre, ES patients are not routinely anticoagulated, as evidence in this and other cohorts of associated PAH is lacking: $[2,20]$ anticoagulation is reserved for patients with previous thromboembolic events, arrhythmias, known in-situ pulmonary artery thrombosis and congestive heart failure, in the absence of contraindications. In-situ thrombosis is, in fact, quite common and is associated with more advanced disease (lower exercise capacity, higher levels of natriuretic peptides and worse ventricular function) [21]. In these patients, anticoagulation should always be considered. With regards to patients on intravenous prostanoids, full anticoagulation should be considered in view of the risk of line-related thrombosis and paradoxic emboli. This, of course, has to be balanced against the risk of bleeding, possibly exacerbated by the antithrombotic properties of prostanoid therapy [22].

B. Pulmonary arterial hypertension associated with systemic-to-pulmonary shunts (and moderate-tolarge defects)

Patients in this group, by definition, have milder forms of PAH compared to Eisenmenger patients, not high enough to cause reversal of the shunt. In the presence of a left-to-right shunt, accurate calculation of pulmonary vascular resistance (PVR) is essential [1]. Indeed, the shunt itself can cause an increase in pulmonary arterial pressure, with little or no PVD, making such patients amenable to repair of the defect. In the presence of a high PVR, patients 
are likely to do better without repair, as the defect acts as a relief valve for the overloaded right ventricle. Cut-offs for indexed PVR were recently proposed at the World Pulmonary Hypertension Symposium in Nice (2013) and most recent guidelines (Table 2), but there is little evidence to support these or other haemodynamic cut-offs $[2,6]$. Thus, decision to close or not a defect should be left to experienced centres, especially for borderline cases in the "grey area".

C. Pulmonary arterial hypertension associated with small (coexistent) defects

These are patients in whom the pulmonary hypertension cannot be explained by the small intracardiac defect. In a few cases, a large ventricular septal defect causing the development of PAH can become smaller over time (e.g. partially covered by tricuspid valve tissue in the case of perimembranous defects). However, in the majority of cases in this group, the development of PAH may be attributable to an intrinsic predisposition of the pulmonary vascular bed, perhaps triggered by the presence of the defect. Patients in this group tend to present and behave like those with idiopathic pulmonary hypertension and repair of the defect is generally contraindicated [2].

D. Pulmonary arterial hypertension after corrective cardiac surgery

This is a growing population and is likely to overtake ES in prevalence over the next decade. These are patients in who PAH persists or develops after repair of the defect. PVD may be mild to severe, and the absence of a defect means that the right ventricle (RV) lacks a "relief valve" $[1,23]$. Hence, depending on the severity of the PVD, clinical presentation can be quite severe and rapidly progressive compared to adult ES and demand aggressive management [7].

E. Additional types of PAH-CHD

"Segmental pulmonary hypertension" refers to PVD which involves portions of the pulmonary vascular bed $[1,24]$. This is not uncommon in CHD, as pulmonary vasculature can be partially "protected" (from developing PVD) by peripheral pulmonary stenosis, congenital or acquired atresia of one the pulmonary arteries (e.g. after a Blalock-Taussig shunt

Table 2 Proposed criteria for closing cardiac shunts in PAHCHD [6]

\begin{tabular}{lll}
\hline PVRI, WU $\times m^{2}$ & PVR, WU & Correctable \\
\hline$<4$ & $<2.3$ & Yes \\
$>8$ & $>4.6$ & No \\
$4-8$ & $2.3-4.6$ & "Grey zone": evaluate in specialist centres \\
\hline $\begin{array}{l}\text { PVRI pulmonary vascular resistance indexed, } W U \text { wood units, } \mathrm{m}^{2} \text { square } \\
\text { meters, PVR Pulmonary vascular resistance }\end{array}$
\end{tabular}

or "slipped" pulmonary artery band) or complex pulmonary atresia. In the latter, the presence of alternative sources of pulmonary perfusion by means of multiple aortopulmonary collaterals (MAPCAs) of various sizes and palliative shunts (e.g. Waterstone or Blalock-Taussig shunts) can result in areas of the lung being excessively perfused, which can develop PVD. There is currently little evidence to support treatment of these patients with PAH therapies. Segmental pulmonary hypertension has been added to group 5 (pulmonary hypertension with unclear and/or multifactorial mechanisms) of the classification of pulmonary hypertension in recent guidelines [2]. In patients with a univentricular heart and a Fontan circulation, PVD may also be present, in the absence of significantly raised PA pressure. Patients with a "failing Fontan" and no significant ventricular or valve dysfunction may have a low pulmonary blood flow and raised PVR. In the absence of a subpulmonary ventricle, this results in a further rise in central venous pressure, congestion and further decline in cardiac output. Treatment of such patients with PAH therapies have been advocated but data remain contoversial [25].

\section{Diagnosis: invasive and non-invasive}

The diagnosis of $\mathrm{PAH}$ in patients with CHD often requires high levels of expertise. Echocardiography and cardiac catheterisation are the mainstay of diagnosis, but important clues can be obtained on physical examination, electrocardiography, chest X-ray, computed tomography and magnetic resonance imaging [26-28].

Echocardiography may be deemed sufficient for establishing the presence of systemic levels of pulmonary arterial pressure in cyanotic patients with post-tricuspid defects and a low-velocity bidirectional shunt (Eisenmenger ventricular septal defect, atrioventricular septal defect and at times patent ductus arteriosus), for the purpose of avoiding invasive assessment. However, cardiac catheterisation is essential for the calculation of PVR in all pretricuspid shunts and all non-cyanotic patients or those with persistent left-right shunt [1]. It is also essential in patients with previously repaired defects and those with a Fontan circulation. Accurate estimation of pulmonary blood flow using the direct Fick principle (not thermodilution) and, thus, PVR is recommended. However, this is not straight-forward in patients with more than one sources of flow to the lungs (patent ductus arteriosus, Fontan circulation with a Glenn anastomosis) and those with complex intracardiac anatomy (e.g. double inlet left ventricle). Hybrid procedures, with calculation of pulmonary blood flow using magnetic resonance imaging have been suggested. 


\section{The management of PAH-CHD}

\section{General management principles}

General management principles which apply to ES and most PAH-CHD include: [1]

- Avoid dehydration, as this can promote hyperviscosity symptoms and affect renal function.

- Avoid extreme isometric exercise, sudden strenuous efforts, which may lead to excessive cyanosis syncopal episodes.

- Avoid high altitude for long periods, as the lower oxygen concentration in ambient air compared to sea level may lead to a decline in resting oxygen saturations and symptomatic deterioration. However, air travel appears to be safe and few patients require supplemental oxygen for relatively short flights $(<4-5 \mathrm{~h})$

- Special anaesthetic management: general anaesthesia and sedation carry significant risks for patients with PAH-CHD. Any essential intervention should be organised in $\mathrm{CHD}$ and $\mathrm{PAH}$ centres, under the care of anaesthetists with experience in such conditions.

- Special care around angiography and non-cardiac surgery: beyond the risk of general anaesthesia, there is a high risk of bleeding in patients with chronic cyanosis and the detrimental effects of pain and analgesia, immobilisation, etc.

- Avoid pregnancy: pregnancy is generally contraindicated in PAH-CHD patients. A high maternal mortality risk is reported $(30-50 \%$ in older series and $17-33 \%$ in more recent papers) in patients with severe $\mathrm{PAH}$ and Eisenmenger syndrome. Adequate (progesteroneonly) contraception is essential, as interruption of pregnancy also carries risks.

- Long-term oxygen rarely used: there is little evidence on the use of long-term oxygen in PAHCHD patients, even in patients with long-standing cyanosis. International guidelines suggest that supplemental O2 therapy should be considered in cases in which it produces a consistent increase in arterial $\mathrm{O}_{2}$ saturation and reduces symptoms (recommendation class IIa, level of evidence C) [2].

- Endocarditis prophylaxis: both the AHA and ESC endocarditis guidelines define cyanotic patients with $\mathrm{CHD}$ as high risk of complications in case of endocarditis (e.g. cerebral abscess) and recommend prophylaxis for dental procedures. This is in contradiction to UK (NICE) guidelines, which recommend prophylaxis for no one. Certainly, good dental and skin hygiene are essential [2].

- Iron deficiency should be sought and treated in all cyanotic patients, as previously discussed, especially when haemoglobin levels are lower than expected for oxygen saturations. Care should be taken to monitor for excessive erythropoiesis after iron

supplementation, even though this appears to be rare.

- Routine venesections are to be avoided: venesection, with fluid replacement, is only recommended in cases with very high haemoglobin or haematocrit and severe hyperviscosity symptoms in the absence of dehydration.

- Aggressive management of chest infections and annual flu vaccine and the pneumococcal vaccine are recommended in all patients. In fact, chest infections can often lead to symptomatic deterioration in these patients through right ventricular failure or sepsis.

- Close monitoring of patients with haemoptysis: haemodynamic and airway stability are essential. Causes or facilitators of haemoptysis should be addressed such as anticoagulation, chest infections, strenuous effort or progression of PAH.

\section{Pulmonary arterial hypertension therapies in PAH-CHD}

BREATHE- 5 is the largest trial performed in PAH-CHD, demonstrating the safety (no decline in oxygen saturations) and efficacy (improvement in PVR and 6-min walk distance, as well as functional class) of bosentan, an endothelin receptor antagonist in adult Eisenmenger patients [29]. The beneficial effect was maintained during the 1 year open label extension [30]. To date, there is little evidence on the use of other endothelin receptor antagonists in PAH-CHD. A large randomised trial of macitentan in Eisenmenger patients is on-going. Recent guidelines recommend the use of bosentan in ES in functional class III (recommendation class I, evidence level B) but also recommend that other PAH therapies are considered (recommendation class IIA, evidence level C) [2].

PDE-5 inhibitors (sildenafil or tadalafil) are widely used despite lack of large randomized trials in this population. Sildenafil has been shown to be safe and effective in small randomized trial and other studies, improving exercise capacity, functional class and hemodynamics [31]. An investigator-led randomized cross-over trial of tadalafil in 28 adult Eisenmenger patients showed an increase in 6MWT distance and decrease in PVR, with improvement in functional class [32].

Limited evidence exists on the use of prostanoids in adults with PAH-CHD [33]. Prostanoid therapy is often reserved for patients in functional class 4 , with some concerns expressed with regards to line infections that could lead to endocarditis, and systemic embolic phenomena in cyanotic patients. Inhaled or subcutaneous prostanoid formulations are potential alternatives, even though small case series have shown good tolerability of IV epoprostenol, with significant benefit in terms of exercise capacity, haemodynamics and oxygen saturation. 
Few adult patients with PAH-CHD and a repaired defect have benefitted from inclusion in the numerous large trials of PAH therapies in idiopathic PAH and $\mathrm{PAH}$ related to connective tissue disease. Longitudinal studies have now demonstrated a long-term benefit from the use of PAH-therapies in PAH-CHD, in terms of exercise capacity and functional state, despite the progressive nature of the disease [5]. Moreover, evidence of an improvement in survival with PAH-therapies is now available from a retrospective propensity score adjusted single centre study on a large number of ES patients [4]. While combination therapy is routinely used in PAHCHD, little evidence exists to support this [34, 35]. Current guidelines recommend that combination drug therapy may be considered in ES (recommendation class IIb, evidence level C), while calcium channel blockers should be avoided [2].

\section{Transplantation}

Transplantation should be considered in all PAH-CHD cases, especially those who have failed oral PAH therapy and are considered for prostanoids. Few centres with combined CHD and transplantation expertise may offer lung transplantation plus repair of the defect and many patients are being listed for heart-lung transplantation. The timing of referral to transplantation is difficult, considering that the 5-year survival rate of patients after heart-lung transplantation is only about $40 \%$ [2]. The discussion with the adult PAH-CHD patient around transplantation may be difficult. Many patients have lived for several decades with PAH-CHD, often exceeding initial estimates of longevity given during childhood. Discussions on transplantation inevitably touch upon prospected survival, causing anxiety to patients and their families. Counselling by the physicians and clinical nurse specialists, as well as clinical psychologists is, thus, essential for limiting such anxiety, whilst providing patients with the best chance of being listed and receiving a transplant.

\section{Living with $\mathrm{PAH}-\mathrm{CHD}$ \\ Complications of $\mathrm{PAH}-\mathrm{CHD}$ and impact on lifestyle}

Beyond improving outcome, what needs to be considered in the setting of counselling and advising PAH$\mathrm{CHD}$ patients is the specific impact that the disease has on their quality of life, i.e. living with this condition [36]. It would be a mistake to presume that patients with PAH-CHD have good knowledge of their condition and its effects on everyday life. Counselling should focus on maintaining a healthy lifestyle, reducing the risk of acute illness and disease progression, while empowering patients to manage uncertainty and live well with the disease. Clinical nurse specialist-led clinics are ideal for addressing such key areas. The merits and worth of the
CNS have been described and are measurable [37]. Their role should reflect a high standard of practice, aimed at achieving high-quality, patient-centred care. The pulmonary hypertension CNS undergoes extensive training on all aspects of the disease and is able to manage both stable and deteriorating patients. They are instrumental in helping physicians achieve the correct diagnosis but especially formulate and implement a management plan that will optimise outcomes and improve quality of life. They are ideally placed in communicating with patients at all stages of their disease, especially with regards to living with pulmonary hypertension and regularly attending clinics [38]. CNSs are best placed for discussing prognosis, complex therapies and their complications, palliative care and end-of-life care issues with the patients. Indeed, the CNS has a central, overarching role in the multidisciplinary approach to pulmonary hypertension, with a remit which is broader than just that of a healthcare provider. They are also researchers, educators and friends to the patients $[39,40]$.

Reducing the risk of acute illness and associated complications is important, both in terms of quality of life and outcome. A common cause of hospitalisation in $\mathrm{PAH}-\mathrm{CHD}$ is lower respiratory tract infections, which can exacerbate the underlying disease and trigger haemoptysis. Haemoptysis is not uncommon in PAH-CHD and is an emergency situation, which generally requires admission to hospital [41]. It is a frightening experience for patients, as it is a potential cause of death and requires prompt care, depending on its severity. Recurrent haemoptysis is not uncommon, significantly affecting patients' quality of life.

Another potentially devastating complication of PAH$\mathrm{CHD}$ is endocarditis [42]. PAH-CHD patients are at greater risk of complications, which are not easily managed. Any surgery, especially cardiac surgery, carries prohibitive risks relating to the general anaesthesia and cardiopulmonary by-pass. There is also a high risk of systemic emboli and the development of a brain abscess: neurological symptoms should never be ignored in cyanotic PAH-CHD patients, even in the absence of overt endocarditis.

Patient education emphasises on early detection of signs and symptoms of the above complications, triggering assessment by the general practitioner or specialist PAH-CHD service. When required, early treatment of lower respiratory tract infections with antibiotics is indicated, reducing the risk of deterioration and the need for hospitalisation. Patients should flag new signs and symptoms of deteriorating heart failure or persistent palpitations requiring prompt attention. They should understand the importance of preventive measures for endocarditis, such as good dental hygiene and avoidance of body piercing or tattoos. Patients should also be able 
to recognise the signs and symptoms of endocarditis and understand modern recommendations for endocarditis prophylaxis: despite on-going controversy and divergence between UK (NICE) and European or American recommendations, clear and consistent advice should be provided to patients and adhered to.

It is important that all $\mathrm{PAH}-\mathrm{CHD}$ patients remain active within their abilities, avoiding detraining and obesity, which can lead to a decline in effort tolerance [43]. Patients should be urged to increase their levels of stamina slowly, through gradual low intensity aerobic exercise, avoiding isometric or sudden/strenuous effort. The advice can be prescriptive for some and there is, indeed, evidence that a tailored rehabilitation programme can greatly improve exercise capacity in PAH [44]. However simple advice on walking and swimming, combined with a healthy diet is acceptable.

There is little evidence for or against long-term oxygen use in PAH-CHD (outside acute exacerbations, chest infections etc.). Long-term oxygen is acceptable as long as it does not impose restriction on personal activities and lifestyle. Anecdotally, patients report three different scenarios/responses when long-term oxygen is prescribed: it either gives them an extra "boost of energy", it makes no noticeable difference or it makes things worse, e.g. due to dry nasal passages and disturbed sleep. It may, at times, be difficult to wean patients off long-term oxygen, when it is perceived as a "crutch" to life. While oxygen is often prescribed for use while travelling in commercial aircraft, there is evidence of safe travelling without it [45]. Standard fitness to fly testing does not account for ES physiology and will invariably conclude that oxygen is required, making it unhelpful. However, travelling at high altitude for long periods (days or weeks) may not be advisable for cyanotic patients with PAH-CHD.

Pregnancy carries prohibitive risks in $\mathrm{PAH}-\mathrm{CHD}$ and contraception is imperative, avoiding oestrogen-containing compounds [46, 47]. Most deaths tend to occur in the last trimester of pregnancy and especially in the days, weeks or even months after delivery, relating to pulmonary hypertensive crises, right heart failure or thrombotic events. Even though patients with higher pulmonary pressures are at higher risk of complications, even patients with milder forms of PAH are at risk, as pregnancy may trigger a progression of PAH. Moreover, there are significant risks to the fetus/baby, not only in relation to the high risk of early miscarriage due to maternal cyanosis, but also relating to prematurity and low birth weight. Despite this and adequate counselling, maternal drive for some women is high. Patients must never feel deterred from seeking expert help from the pulmonary hypertension centre when seeking pregnancy, despite strong advice against this. Pregnant PAH-CHD patients should be aided in making the difficult decision: continue with the pregnancy or choose termination. Whichever option is taken, multidisciplinary specialist care is essential.

To live well with PAH-CHD, there are basic socioeconomic factors relating to education, work life and welfare rights that need to be appreciated and discussed in clinic. Milestones of adult development might be slower and more difficult to achieve in patients with PAHCHD. Help should be provided in making realistic choices for the future, including education and employment. Support should be provided by specialist teams to patients who are eager but fail to cope with full or parttime occupation, in the form of letters of support and guidance with regards to adjusting the work environment. Employment law might need to be referenced to protect both employee and employer and achieve a balanced outcome. For patients unable to work, an overview of welfare law and entitlement is necessary, directing patients to expert advice such as the Citizens Advice Bureau. Patient associations can be helpful in these circumstances.

\section{Managing therapies, including inhaled and intravenous prostanoids: the role of the clinical nurse specialist (CNS)}

Starting a patient on PAH therapies requires significant input from both physicians and the CNSs. Whether it is for oral, inhaled or intravenous treatment, a process of education, monitoring and support is required. Indeed, patient adherence is essential if treatment outcomes are to be maximised. Oral medication is relatively easily managed, provided that patients are educated on side effect profiles and the need for adherence. It is particularly important that patients are well aware of possible visual and hearing impairment, which can be permanent with PDE-5 inhibitors. Monthly liver function testing remains a legal obligation for most ERAs in most countries. Female patients are counselled on interaction of bosentan with progesterone based contraception and the need for double contraception for all ERAs. Emerging new oral therapies, such as riociguat and selexipag, will eventually find their place in the treatment of PAH-CHD. Uptitration of these drugs can be more complex, requiring several weeks of close contact with the pulmonary hypertension clinical team, especially CNSs.

Initiation of inhaled and intravenous prostacyclines is more onerous in terms of time required to educate and monitor patients. Training to use the inhaled iloprost, with the I-neb nebuliser, is moderately straight forward, but patients need to understand the importance of adhering to a regime of at least six inhalations a day, as well as being meticulous in cleaning the components of the I-neb after each use. Inhalation time can range between 10 and 20 min:The I-neb uses adaptive aerosol delivery technology to deliver the drug and adapts to each patient's breathing pattern. The inhalation time is, therefore, dependant on several factors including the 
breathing pattern of the patient, number of pauses made during treatment and appropriate cleaning of the chamber mesh lid. Inhalation time can be prolonged if the fine mesh consumable is not cleaned as instructed and, indeed, can affect compliance. A daily care kit has been manufactured to help with the inconvenience of taking the medication frequently. The treatment is well tolerated and side effects rarely lead to discontinuation. The I-neb itself can be interrogated for patient education on adherence, as the device stores information on each inhalation and its duration.

Intravenous epoprostenol is, by many experts, felt to be the strongest available PAH-therapy [22]. Even more so than inhaled iloprost, it requires a high level of commitment by the patient and requires strategic planning to accommodate into a patient's life. As patients come to terms with the thought of living with a central venous catheter, a drug seen as the "final resort" with perils and the discomfort relating to its short half-life and debilitating side effects, it can take time and effort before treatment can be started electively. Some patients will adapt more easily than others, especially if they can be convinced that their quality of life and life expectancy can improve with this medication. An intensive training programme is part of the initiation of intravenous epoprostenol, including aseptic and non-touch techniques for line management and drug reconstitution, as well as managing and troubleshooting the infusion pump. Comprehensive paperwork should be provided to the patient on how the pump and infusion should be managed in a local casualty department in case of emergency, as well as the need to contact the specialist centre to arrange urgent transfer, if required. On-going fears for healthcare workers and especially the patients include line infections, progressive loss of efficacy and funding issues, which may require withdrawal of other, previously effective medication. The advent of thermostable epoprostenol has made the prospect of living with intravenous therapy more acceptable: this new product can be infused for up to $48 \mathrm{~h}$ (as opposed to $12 \mathrm{~h}$ for previous formulations) and can be reconstituted up to a week in advance, if kept in the refrigerator [48].

\section{End of life issues and palliative care}

Despite advances in the modern treatment of PAH$\mathrm{CHD}$, it is a progressive disease, which is ultimately lifelimiting. Early involvement of palliative care services can be helpful and should follow the natural history of the disease, rather than be reserved for the end of life. While extensive literature exists on how to approach palliative care and end-of-life issues in patients with chronic diseases, lifelong support by the pulmonary hypertension team and especially the CNSs is essential and remains a matter of experience, instinct, the art of nursing and medicine combined and the ability to build a relation of trust with the patients. Effective communication with the patients and their families is particularly important as the disease progresses and especially towards the end of life. While palliative care services should be involved as early as possible in the care of these patients, the CNS is central in achieving adequate levels of support, both from a symptom and a psychological point of view [49]. The CNSs also helps co-ordinate individual care plans and remains the point of contact for other professionals in the hospital or the community and for the patients and their families.

\section{Conclusions}

$\mathrm{PAH}-\mathrm{CHD}$ is a condition that carries significant morbidity and mortality. Expertise in both pulmonary hypertension and CHD is required for the optimal management of these patients, as well as a multidisciplinary approach in which both physicians and nurse specialists play an important role. It is important that all PAH-CHD patients are identified and treated appropriately, aiming to improve not only their outcome but also their quality of life.

\section{Abbreviations}

CHD: Congenital heart disease; CNS: Clinical nurse specialist; ES: Eisenmenger syndrome; PAH: Pulmonary arterial hypertension; PAH-CHD: Pulmonary arterial hypertension related to congenital heart disease; PVD: Pulmonary vascular disease; PVR: Pulmonary vascular resistance; RV: Right ventricle

\section{Authors' contributions}

KD and CH drafted the paper, which was critically reviewed by LP. All authors read and approved the final manuscript.

\section{Competing interests}

The authors have received educational grants and/or acted as consultants for Pfizer, Actelion, GSK and Bayer.

Ethics approval and consent to participate

Ethics approval was not required.

\section{Publisher's Note}

Springer Nature remains neutral with regard to jurisdictional claims in published maps and institutional affiliations.

Received: 21 July 2015 Accepted: 26 June 2017

Published online: 28 July 2017

References

1. Dimopoulos K, Wort SJ, Gatzoulis MA. Pulmonary hypertension related to congenital heart disease: a call for action. Eur Heart J. 2014;35:691-700.

2. Authors/Task Force Members, Galiè N, Humbert M, Vachiery J-L, Gibbs S, Lang I, Torbicki A, Simonneau G, Peacock A, Vonk Noordegraaf A, Beghetti M, Ghofrani A, Gomez Sanchez MA, Hansmann G, Klepetko W, Lancellotti P, Matucci M, McDonagh T, Pierard LA, Trindade PT, Zompatori M, Hoeper M. 2015 ESC/ERS Guidelines for the diagnosis and treatment of pulmonary hypertension: The Joint Task Force for the Diagnosis and Treatment of Pulmonary Hypertension of the European Society of Cardiology (ESC) and the European Respiratory Society (ERS)Endorsed by: Association for European Paediatric and Congenital Cardiology (AEPC), International Society for Heart and Lung Transplantation (ISHLT). Eur Heart J. 2016;37:67-119

3. Diller G-P, Kempny A, Alonso-Gonzalez R, Swan L, Uebing A, Li W, Babu-Narayan S, Wort SJ, Dimopoulos K, Gatzoulis MA. Survival Prospects and Circumstances of Death in Contemporary Adult Congenital Heart Disease Patients Under Follow-Up at a Large Tertiary Centre. Circulation 2015;132:2118-25. 
4. Dimopoulos K, Inuzuka R, Goletto S, Giannakoulas G, Swan L, Wort SJ, Gatzoulis MA. Improved survival among patients with Eisenmenger syndrome receiving advanced therapy for pulmonary arterial hypertension. Circulation. 2010;121:20-5.

5. Diller G-P, Alonso-Gonzalez R, Dimopoulos K, Alvarez-Barredo M, Koo C, Kempny A, Harries C, Parfitt L, Uebing AS, Swan L, Marino PS, Wort SJ, Gatzoulis MA. Disease targeting therapies in patients with Eisenmenger syndrome: Response to treatment and long-term efficiency. Int J Cardiol. 2013;167:840-7.

6. Simonneau G, Gatzoulis MA, Adatia I, Celermajer D, Denton C, Ghofrani A, Gomez Sanchez MA, Krishna Kumar R, Landzberg M, Machado RF, Olschewski H, Robbins IM, Souza R. Updated clinical classification of pulmonary hypertension. J Am Coll Cardiol. 2013;62:D34-41.

7. Manes A, Palazzini M, Leci E, Bacchi Reggiani ML, Branzi A, Galiè N. Current era survival of patients with pulmonary arterial hypertension associated with congenital heart disease: a comparison between clinical subgroups. Eur Heart J. 2014;35:716-24.

8. Dimopoulos K, Diller G-P, Koltsida E, Pijuan-Domenech A, Papadopoulou SA, Babu-Narayan SV, Salukhe TV, Piepoli MF, Poole-Wilson PA, Best N, Francis DP, Gatzoulis MA. Prevalence, predictors, and prognostic value of renal dysfunction in adults with congenital heart disease. Circulation. 2008;117:2320-8.

9. Dimopoulos K, Giannakoulas G, Wort SJ, Gatzoulis MA. Pulmonary arterial hypertension in adults with congenital heart disease: distinct differences from other causes of pulmonary arterial hypertension and management implications. Curr Opin Cardiol. 2008;23:545-54.

10. Kempny A, Dimopoulos K, Alonso-Gonzalez R, Alvarez-Barredo M, Tutarel O, Uebing A, Piatek P, Marino P, Swan L, Diller G-P, Wort SJ, Gatzoulis MA. Sixminute walk test distance and resting oxygen saturations but not functional class predict outcome in adult patients with Eisenmenger syndrome. Int J Cardiol. 2013;168:4784-9.

11. Kempny A, Diller G-P, Alonso-Gonzalez R, Uebing A, Rafiq I, Li W, Swan L, Hooper J, Donovan J, Wort SJ, Gatzoulis MA, Dimopoulos K. Hypoalbuminaemia predicts outcome in adult patients with congenital heart disease. Heart $\mathrm{Br}$ Card Soc. 2015;101:699-705.

12. Kempny A, Dimopoulos K, Uebing A, Moceri P, Swan L, Gatzoulis MA, Diller G-P. Reference values for exercise limitations among adults with congenital heart disease. Relation to activities of daily life-single centre experience and review of published data. Eur Heart J. 2012;33:1386-96.

13. Diller G-P, Dimopoulos K, Okonko D, Li W, Babu-Narayan SV, Broberg CS, Johansson B, Bouzas B, Mullen MJ, Poole-Wilson PA, Francis DP, Gatzoulis MA. Exercise intolerance in adult congenital heart disease: comparative severity, correlates, and prognostic implication. Circulation. 2005;112:828-35.

14. Dimopoulos K, Okonko DO, Diller G-P, Broberg CS, Salukhe TV, BabuNarayan SV, Li W, Uebing A, Bayne S, Wensel R, Piepoli MF, Poole-Wilson PA, Francis DP, Gatzoulis MA. Abnormal ventilatory response to exercise in adults with congenital heart disease relates to cyanosis and predicts survival. Circulation. 2006:113:2796-802.

15. Oechslin E. Hematological management of the cyanotic adult with congenital heart disease. Int J Cardiol. 2004;97 Suppl 1:109-15.

16. Perloff JK, Rosove MH, Child JS, Wright GB. Adults with cyanotic congenital heart disease: hematologic management. Ann Intern Med. 1988;109:406-13.

17. Spence MS, Balaratnam MS, Gatzoulis MA. Clinical update: cyanotic adult congenital heart disease. Lancet. 2007;370:1530-2.

18. Ammash $\mathrm{N}$, Warnes CA. Cerebrovascular events in adult patients with cyanotic congenital heart disease. J Am Coll Cardiol. 1996:28:768-72.

19. Sandoval J, Santos LE, Córdova J, Pulido T, Gutiérrez G, Bautista E, Martinez Guerra ML, Peña H, Broberg CS. Does Anticoagulation in Eisenmenger Syndrome Impact Long-term Survival? Congenit Heart Dis. 2012;7:268-76.

20. Olsson KM, Delcroix M, Ghofrani HA, Tiede H, Huscher D, Speich R, Grünig E, Staehler G, Rosenkranz S, Halank M, Held M, Lange TJ, Behr J, Klose H, Claussen M, Ewert R, Opitz CF, Vizza CD, Scelsi L, Vonk-Noordegraaf A, Kaemmerer H, Gibbs JSR, Coghlan G, Pepke-Zaba J, Schulz U, Gorenflo M, Pittrow D, Hoeper MM. Anticoagulation and survival in pulmonary arterial hypertension: results from the Comparative, Prospective Registry of Newly Initiated Therapies for Pulmonary Hypertension (COMPERA). Circulation. 2014;129:57-65.

21. Broberg CS, Ujita M, Prasad S, Li W, Rubens M, Bax BE, Davidson SJ, Bouzas B, Gibbs JSR, Burman J, Gatzoulis MA. Pulmonary arterial thrombosis in eisenmenger syndrome is associated with biventricular dysfunction and decreased pulmonary flow velocity. J Am Coll Cardiol. 2007:50:634-42.

22. Thomas IC, Glassner-Kolmin C, Gomberg-Maitland M. Long-term effects of continuous prostacyclin therapy in adults with pulmonary hypertension associated with congenital heart disease. Int J Cardiol. 2013;168:4117-21.

23. Alonso-Gonzalez R, Lopez-Guarch CJ, Subirana-Domenech MT, Ruíz JMO, González IO, Cubero JS, Del Cerro MJ, Salvador ML, Subira LD, Gallego P, Escribano-Subias P. REHAP investigators. Pulmonary hypertension and congenital heart disease: An insight from the REHAP National Registry. Int J Cardiol. 2015:184:717-23.

24. Schuuring MJ, Bouma BJ, Cordina R, Gatzoulis MA, Budts W, Mullen MP, Vis JC, Celermajer D, Mulder BJM. Treatment of segmental pulmonary artery hypertension in adults with congenital heart disease. Int J Cardiol. 2013;164:106-10.

25. Hebert A, Mikkelsen UR, Thilen U, Idorn L, Jensen AS, Nagy E, Hanseus K, Sørensen KE, Søndergaard L. Bosentan improves exercise capacity in adolescents and adults after Fontan operation: the TEMPO (Treatment With Endothelin Receptor Antagonist in Fontan Patients, a Randomized, PlaceboControlled, Double-Blind Study Measuring Peak Oxygen Consumption) study. Circulation. 2014;130:2021-30.

26. Moceri P, Dimopoulos K, Liodakis E, Germanakis I, Kempny A, Diller G-P, Swan L, Wort SJ, Marino PS, Gatzoulis MA, Li W. Echocardiographic predictors of outcome in eisenmenger syndrome. Circulation. 2012;126:1461-8.

27. Moceri P, Kempny A, Liodakis E, Alonso Gonzales R, Germanakis I, Diller G-P, Swan L, Marino PS, Wort SJ, Babu-Narayan SV, Ferrari E, Gatzoulis MA, Li W, Dimopoulos K. Physiological differences between various types of Eisenmenger syndrome and relation to outcome. Int J Cardiol. 2015;179:455-60.

28. Dimopoulos K, Giannakoulas G, Bendayan I, Liodakis E, Petraco R, Diller G-P, Piepoli MF, Swan L, Mullen M, Best N, Poole-Wilson PA, Francis DP, Rubens MB, Gatzoulis MA. Cardiothoracic ratio from postero-anterior chest radiographs: A simple, reproducible and independent marker of disease severity and outcome in adults with congenital heart disease. Int J Cardiol. 2013;166:453-7.

29. Galiè N, Beghetti M, Gatzoulis MA, Granton J, Berger RMF, Lauer A, Chiossi E, Landzberg M. Bosentan therapy in patients with Eisenmenger syndrome: a multicenter, double-blind, randomized, placebo-controlled study. Circulation. 2006;114:48-54

30. Gatzoulis MA, Beghetti M, Galiè N, Granton J, Berger RMF, Lauer A, Chiossi E, Landzberg M. Longer-term bosentan therapy improves functional capacity in Eisenmenger syndrome: results of the BREATHE-5 open-label extension study. Int J Cardiol. 2008;127:27-32.

31. Tay ELW, Papaphylactou M, Diller GP, Alonso-Gonzalez R, Inuzuka R, Giannakoulas G, Harries C, Wort SJ, Swan L, Dimopoulos K, Gatzoulis MA. Quality of life and functional capacity can be improved in patients with Eisenmenger syndrome with oral sildenafil therapy. Int J Cardiol. 2011;149:372-6.

32. Mukhopadhyay S, Nathani S, Yusuf J, Shrimal D, Tyagi S. Clinical efficacy of phosphodiesterase-5 inhibitor tadalafil in Eisenmenger syndrome-a randomized, placebo-controlled, double-blind crossover study. Congenit Heart Dis. 2011;6:424-31.

33. Fernandes SM, Newburger JW, Lang P, Pearson DD, Feinstein JA, Gauvreau K, Landzberg MJ. Usefulness of epoprostenol therapy in the severely ill adolescent/adult with Eisenmenger physiology. Am J Cardiol. 2003;91:632-5.

34. Iversen K, Jensen AS, Jensen TV, Vejlstrup NG, Søndergaard L. Combination therapy with bosentan and sildenafil in Eisenmenger syndrome: a randomized, placebo-controlled, double-blinded trial. Eur Heart J. 2010;31:1124-31.

35. D'Alto M, Romeo E, Argiento P, Sarubbi B, Santoro G, Grimaldi N, Correra A, Scognamiglio G, Russo MG, Calabrò R. Bosentan-sildenafil association in patients with congenital heart disease-related pulmonary arterial hypertension and Eisenmenger physiology. Int J Cardiol. 2012;155:378-82

36. Callus E, Utens EMWJ, Quadri E, Ricci C, Carminati M, Giamberti A, Chessa M. The impact of actual and perceived disease severity on pre-operative psychological well-being and illness behaviour in adult congenital heart disease patients. Cardiol Young. 2014;24:275-82.

37. Leary A. Proving your worth [Internet]. Available from: http://alisonleary.co. uk/docs/Proving\%20your\%20worth\%20(CNS\%20all\%20specialisms).pdf. Accessed 7 Nov 2015.

38. Kempny A, Diller G-P, Dimopoulos K, Alonso-Gonzalez R, Uebing A, Li W, Babu-Narayan S, Swan L, Wort SJ, Gatzoulis MA. Determinants of outpatient 
clinic attendance amongst adults with congenital heart disease and outcome. Int J Cardiol. 2015;203:245-50.

39. Harries $C$, Armstrong I. A review of the management of pulmonary arterial hypertension associated with congenital heart disease. Eur J Cardiovasc Nurs J Work Group Cardiovasc Nurs Eur Soc Cardiol. 2012;11:239-47.

40. Yorke J, Corris P, Gaine S, Gibbs JSR, Kiely DG, Harries C, Pollock V, Armstrong I. emPHasis-10: development of a health-related quality of life measure in pulmonary hypertension. Eur Respir J. 2014;43:1106-13.

41. Broberg C, Ujita M, Babu-Narayan S, Rubens M, Prasad SK, Gibbs JSR, Gatzoulis MA. Massive pulmonary artery thrombosis with haemoptysis in adults with Eisenmenger's syndrome: a clinical dilemma. Heart Br Card Soc. 2004;90, e63.

42. Authors/Task Force Members, Habib G, Lancellotti P, Antunes MJ, Bongiorni MG, Casalta J-P, Del Zotti F, Dulgheru R, El Khoury G, Erba PA, lung B, Miro JM, Mulder BJ, Plonska-Gosciniak E, Price S, Roos-Hesselink J, Snygg-Martin U, Thuny F, Tornos Mas P, Vilacosta I, Zamorano JL. 2015 ESC Guidelines for the management of infective endocarditis: The Task Force for the Management of Infective Endocarditis of the European Society of Cardiology (ESC) Endorsed by: European Association for Cardio-Thoracic Surgery (EACTS), the European Association of Nuclear Medicine (EANM). Eur Heart J. 2015;36:3075-128.

43. Budts W, Börjesson M, Chessa M, van Buuren F, Trigo Trindade P, Corrado D, Heidbuchel H, Webb G, Holm J, Papadakis M. Physical activity in adolescents and adults with congenital heart defects: individualized exercise prescription. Eur Heart J. 2013;34:3669-74.

44. Buys R, Avila A, Cornelissen VA. Exercise training improves physical fitness in patients with pulmonary arterial hypertension: a systematic review and meta-analysis of controlled trials. BMC Pulm Med. 2015;15:40.

45. Broberg CS, Uebing A, Cuomo L, Thein SL, Papadopoulos MG, Gatzoulis MA. Adult patients with Eisenmenger syndrome report flying safely on commercial airlines. Heart Br Card Soc. 2007;93:1599-603.

46. Bédard E, Dimopoulos K, Gatzoulis MA. Has there been any progress made on pregnancy outcomes among women with pulmonary arterial hypertension? Eur Heart J. 2009;30:256-65.

47. European Society of Gynecology (ESG), Association for European Paediatric Cardiology (AEPC), German Society for Gender Medicine (DGesGM), ESC Committee for Practice Guidelines, Regitz-Zagrosek V, Blomstrom Lundqvist C, Borghi C, Cifkova R, Ferreira R, Foidart J-M, Gibbs JSR, Gohlke-Baerwolf C, Gorenek B, lung B, Kirby M, Maas AHEM, Morais J, Nihoyannopoulos P, Pieper PG, Presbitero P, Roos-Hesselink JW, Schaufelberger M, Seeland U, Torracca L. ESC Guidelines on the management of cardiovascular diseases during pregnancy: the Task Force on the Management of Cardiovascular Diseases during Pregnancy of the European Society of Cardiology (ESC). Eur Heart J. 2011;32:3147-97.

48. Provencher S, Paruchuru P, Spezzi A, Waterhouse B, Gomberg-Maitland M. pH12 Flolan reformulation study group. Quality of life, safety and efficacy profile of thermostable flolan in pulmonary arterial hypertension. PloS One. 2015;10, e0120657.

49. Diller G-P, Bräutigam A, Kempny A, Uebing A, Alonso-Gonzalez R, Swan L, Babu-Narayan SV, Baumgartner H, Dimopoulos K, Gatzoulis MA. Depression requiring anti-depressant drug therapy in adult congenital heart disease: prevalence, risk factors, and prognostic value. Eur Heart J 2016;37:771-82.

\section{Submit your next manuscript to BioMed Central and we will help you at every step:}

- We accept pre-submission inquiries

- Our selector tool helps you to find the most relevant journal

- We provide round the clock customer support

- Convenient online submission

- Thorough peer review

- Inclusion in PubMed and all major indexing services

- Maximum visibility for your research

Submit your manuscript at www.biomedcentral.com/submit 